\title{
Don Víctor Huamán Reyes: el «cacique moral» de Cañaris
}

Don Víctor Huamán Reyes: le «cacique moral» de Cañaris

Don Victor Huamán Reyes: the «cacique moral» of Cañaris

\section{Pedro Alva Mariñas}

\section{(2) OpenEdition} Journals

\section{Edición electrónica}

URL: http://journals.openedition.org/bifea/3483

DOI: 10.4000/bifea.3483

ISSN: 2076-5827

\section{Editor}

Institut Français d'Études Andines

Edición impresa

Fecha de publicación: 1 abril 2008

Paginación: 257-270

ISSN: 0303-7495

Referencia electrónica

Pedro Alva Mariñas, « Don Víctor Huamán Reyes: el «cacique moral» de Cañaris », Bulletin de l'Institut français d'études andines [En línea], 37 (1) | 2008, Publicado el 01 octubre 2008, consultado el 27 noviembre 2020. URL : http://journals.openedition.org/bifea/3483 ; DOI : https://doi.org/10.4000/ bifea.3483

Les contenus du Bulletin de l'Institut français d'études andines sont mis à disposition selon les termes de la licence Creative Commons Attribution - Pas d'Utilisation Commerciale - Pas de Modification 4.0 International. 


\title{
Don Víctor Huamán Reyes: el «cacique moral» de Cañaris
}

\author{
Pedro Alva Mariñas*
}

\begin{abstract}
Resumen
Don Víctor Huamán Reyes, reconocido y llamado «el cacique de Cañaris», se proyecta con el tiempo como un personaje salido de algunos textos de historia, pues asume un liderazgo en distintos campos de la vida de la gente de Cañaris. Lo vemos como un continuador de la labor de sus ancestros, apareciendo en los grandes problemas de su comunidad, prodigando atenciones y hospitalidad a su gente, velando por la permanencia de ciertas tradiciones comunales, entre ellas, los danzantes y la limpia de caminos y practicando buenas costumbres y tratos a los foráneos. Don Víctor ha desempeñado diversos cargos oficiales, pero también varios cargos tradicionales y en tal sentido se ha movido entre dos mundos como la mayoría de los caciques coloniales; sin embargo, son los cargos tradicionales y el hecho de haber sido protagonista de hechos capitales para su comunidad lo que lo han convertido en toda una autoridad andina. Don Víctor Huamán Reyes tiene la apariencia de un simple campesino y sus signos exteriores de riqueza apenas si aparecen, pero rápidamente se nota que goza del respeto y la consideración de mucha gente, de «mi gente» como acostumbra decir... tal vez ahí se encuentre su riqueza.
\end{abstract}

Palabras clave: Cañaris, Lambayeque, cacique moral, tradición, fundador, comunidad

\section{Don Víctor Huamán Reyes: le «cacique moral» de Cañaris}

\section{Résumé}

Don Víctor Huamán Reyes, passé à la postérité comme " le cacique de Cañaris », semble tout droit sorti des livres d'histoire dans la mesure où l'autorité qu'on lui prête recouvre les aspects les plus divers de la vie des habitants de Cañaris. II prend la relève de ses ancêtres en intervenant dans les problèmes importants de sa communauté, en prodiguant attentions et hospitalité à ses membres, en veillant à la continuité de certaines traditions communales, comme celle des danseurs, ou celle de l'entretien des 
chemins, ainsi que celle de la pratique des bonnes coutumes et de l'hospitalité envers les étrangers. Don Víctor a rempli de nombreuses charges officielles mais aussi traditionnelles. Il a donc évolué entre deux mondes comme la plupart des caciques coloniaux ; mais ce sont les charges traditionnelles et son rôle clé à l'occasion d'événements capitaux pour sa communauté qui lui ont valu de se voir conférer un statut d'autorité selon le canon andin. Don Víctor Huamán Reyes a l'aspect d'un simple paysan et ses signes extérieurs de richesse sont à peine visibles, mais l'on perçoit immédiatement qu'il jouit du respect et de la considération du plus grand nombre, des « siens » comme il a coutume de les appeler. C'est de là, vraisemblablement, qu'il tire sa richesse.

Mots clés : Cañaris, Lambayeque, cacique moral, tradition, fondateur, communauté

\title{
Don Víctor Huamán Reyes: the «cacique moral» of Cañaris
}

\begin{abstract}
Don Victor Huaman Reyes, recognized and called «the cacique of Canaris», is projected, through time, as a personage who comes straight out of the history books, because he assumes the leadership of various aspects of the lives of the people of Canaris. We see him as the protector of the ancestral legacy, intervening in the great problems of his community, dispensing attentions and hospitality to the people, watching over the communal traditions, among them, the dancers, the maintenance of the roads, and the practice of good customs and good treatment of outsiders. Don Victor served in various official capacities and also assumed various traditional responsibilities. In this respect, like the majority of colonial caciques, he moved between two worlds; nevertheless, the traditional responsibilities and the fact that he was the protagonist in various transcendent events for his community made him a significant Andean authority. Don Victor Huaman Reyes looked like a simple peasant and his outward signs of wealth were hardly perceivable, but one quickly notes that he enjoyed the respect and consideration of many people, of «his people» as he was accustomed to say. Perhaps, the people were his wealth.
\end{abstract}

Key words: Cañaris, Lambayeque, moral cacique, tradition, founder, community

Estudios especializados sobre los curacas — llamados también caciques_ nos los describen como personajes temidos, respetados y con doble autoridad política y religiosa y cuya legitimidad se basaba en el linaje de sangre del fundador de la comunidad. Su estatus se basaba en el número de personas «sujetas» a su autoridad y para ello requería ciertas dotes de justicia, protección, redistribución y reciprocidad. Ya en tiempos coloniales el curaca aparece como más funcional al sistema, sigue siendo un líder político, organizador de la mita y el trabajo comunal. Su rol religioso se limitaba a dar continuidad a ciertos ritos. Su nombramiento o confirmación dependía de las autoridades coloniales y ello lo incorpora todavía más al engranaje del sistema de explotación. La represión al movimiento de Túpac Amaru debilitó todavía más al cacique hasta llegar a los primeros años de la Independencia en que se lo elimina oficialmente (Cock, 1984; Diez Hurtado, 1988; Espinoza Soriano, 1980; Fernández Villegas, 1991; Glave, 1989; Pease, 1988; Ravines, 1972; Rostworowski, 1961; 1982).

No podía menos que sorprendernos encontrar en años recientes, en las serranías del actual departamento de Lambayeque, a un personaje al que llaman «cacique de Cañaris» y que en cierta forma nos liga con aquel personaje del pasado en funciones de fundador, guardián de 
las tradiciones o memorias de su pueblo, continuador de un linaje, animador de procesos, «dueño» de su gente y cuya riqueza más importante pareciera ser tener el respeto, la obediencia y el aprecio de la gente (Ramírez, 2002). A este personaje lo llamamos «cacique moral» para enfatizar que su autoridad y prestigio no vienen del mundo oficial 1 .

\section{EL CONTEXTO DE ESTA HISTORIA}

Con el término Cañaris estamos designando a un distrito ubicado en las serranías del departamento de Lambayeque, que a su vez se ubica en la costa norte del Perú. Este distrito presenta dos áreas históricamente diferenciadas: una que ocupa la parte oriental del distrito, de larga tradición comunera conocida como común de indios, comunidad de indígenas y más recientemente Comunidad Campesina San Juan de Cañaris; y un espacio ubicado en la parte occidental del distrito, área dominada por haciendas, luego transformadas en grupos campesinos para finalmente conformar la Comunidad Campesina Túpac Amaru II. Finalmente Cañaris es también el nombre del pequeño pueblo que es la capital distrital. Esta historia habla de un líder viviente de la comunidad indígena San Juan de Cañaris.

En la época en que se desenvuelve esta historia — entre 1986 y 1993 - se llegaba al pueblo de Cañaris, caminando o en acémila; no existían hoteles, restaurantes, ni mercado y tampoco se contaba con un puesto policial. La única bodega ofrecía unas cuantas mercancías transportadas con mucho esfuerzo y destinadas mayormente a los docentes locales. La Municipalidad, la dependencia distrital del Ministerio de Educación y la gobernación política eran las únicas instancias del Estado en el distrito. En realidad, el pueblo de Cañaris es más bien un pueblo religioso que recibe visitantes solo para las épocas de fiestas; en particular durante la festividad de San Juan que se celebra el 24 de Junio y cuyo personaje oficial es el sacerdote que visita al pueblo para presidir los oficios religiosos y realizar los bautismos y matrimonios. El distrito de Cañaris presenta un modelo de ocupación dispersa de su territorio pues el grueso de su población vive junto a sus chacras y tiende a aglomerarse en pequeños poblados ya sea alrededor del pequeño templo, ya sea de las escuelas. Resulta explicable entonces que la gente con cierto poder tradicional — como el caso de don Víctor Huamán Reyes_ tenga su residencia permanente en los caseríos y no en la capital distrital.

1 La primera vez que escuché nombrarlo y ver personalmente al cacique de Cañaris fue una tarde del mes de abril de 1986 con motivo de mi presencia en un conversatorio oficial realizado en el pueblo de Cañaris. A partir de ese evento adquirí compromisos de asesoría profesional con la Comunidad Campesina San Juan de Cañaris en la línea de fortalecimiento de su institucionalidad y luego en la delimitación y titulación del territorio comunal. Luego también apoyé a la municipalidad distrital, a la cual accedieron los dirigentes comunales, lo que me permitió estar en Cañaris y realizar varias visitas donde tuve la oportunidad de ver a don Víctor Huamán Reyes. Debo también mencionar que en dos oportunidades pude conversar en la casa del cacique ubicada en el caserío de Atunpampa. Una primera visita se realizó el día 17 de febrero de 1987, a mi regreso de Cañaris y una segunda visita —en la que pernocté en su casa- se realizó a mediados del mes de octubre de 1993, a mi regreso de la celebración del aniversario de la Comunidad Campesina San Juan de Cañaris.

A partir de 1993 los contactos se hicieron más esporádicos, pero nunca he dejado de tener una vinculación personal con pobladores de Cañaris. En todo este tiempo hice una buena amistad con don Víctor Huamán, incluso me ha visitado a Chiclayo en busca de tratamiento para una dolencia «de hombres» como suele llamarle al mal que lo aqueja. Producto de estas incursiones a los cañaris son algunos trabajos publicados: Alva Mariñas (1995a; 1989; 1995b; 1999) y varios artículos de corte periodístico publicados en un diario local.

Una vez redactado este artículo, pude sostener una conversación con el cacique (29 de abril de 2007) durante una corta visita que hiciera a Chiclayo, lo que me ha permitido confirmar, y en otros casos afinar, los datos que hace varios años estaban anotados en mi libreta de apuntes. A pesar de sus 89 años conserva gran parte de su lucidez y su preocupación por su comunidad: «las mineras ya están en Cañaris» me decía, «vengo en busca de un buen padrino para que defienda mi Comunidad». Esto me hace pensar que todavía don Víctor Huamán no ha terminado de escribir su historia. 
Dos marcas de identidad distinguen a los cañaris: el idioma quechua como idioma que es el idioma materno para un alto porcentaje de su población y la vestimenta, especialmente de las mujeres (con variaciones geográficas internas). Por el lado institucional es la Comunidad Campesina San Juan de Cañaris (hasta antes de 1970 se denominaba comunidad indígena) la entidad más representativa ya que la Municipalidad ha ido ganando creciente importancia.

La persistencia de un pueblo quechua hablante no llamaría la atención en el centro o en el sur andino de Perú — porque ello es bastante frecuente—, pero la existencia de un pueblo como los cañaris que ha logrado mantener su idioma y muchas de sus prácticas culturales en condiciones de cerco de la sociedad occidentalizada y de permanente intromisión de la sociedad regional es algo que llama poderosamente la atención y seguramente despertará el interés por explicarla².

\section{NO ES UN PROPIO, ES EL CACIQUE}

En Cañaris, un atardecer del mes de abril del año 1986, las campanas del templo redoblaron anunciando la llegada al pueblo del Presidente de la Corporación Departamental y su comitiva para participar en un conversatorio sobre la problemática del distrito de Cañaris, organizado por las autoridades locales. La comitiva hacía su ingreso a la pequeña plaza en medio de la curiosidad de la gente y el usual ruido combinado de repique de campanas y estruendo de cohetes. Como no había carretera, los comisionados arribaban montados en acémilas recolectadas desde diversos caseríos en una especie de colaboración comunal. De alguna manera se reproducía en mi mente la visita de funcionarios coloniales como el cobrador de impuestos o el teniente de corregidor.

En primera fila de la comitiva, pero a pie y jalando la acémila en que iba montado el alto funcionario, se veía a un hombre ya mayor, de baja estatura, de unos 60 años, con la vestimenta propia de un campesino del lugar. Fue en estos momentos en que escuchamos, por primera vez, la exclamación de uno de los comuneros: «allí está el cacique». Hasta conocerlo, verlo actuar, escuchar lo que hablan de él y finalmente conversar en su natal Atunpampa, simplemente ino se podía creer que los pobladores quechua hablantes de Cañaris lo llamaran cacique! No era pues un propio3, era nada menos que el Cacique de Cañaris.

2 El año 2000, OXFAM América propició la visita de una delegación de comuneros de la provincia de Cañar del Ecuador al distrito de Cañaris perteneciente al departamento de Lambayeque. Luego de un largo y azaroso recorrido, la delegación llegó a la ciudad de Chiclayo y luego se internó con dirección a Cañaris, ubicado en las serranías de Lambayeque. Una vez que llegaron a un punto conocido como San Lorenzo, los expedicionarios cruzaron el río Huancabamba mediante un dispositivo rústico conocido como «huaro». Una vez atravesado el río, la delegación se encontraba entonces en el territorio de los cañaris y allí los esperaba un nutrido grupo de autoridades y dirigentes. Casi sin abrazos y hasta silenciosos se pusieron de acuerdo en celebrar este «reencuentro de los 500 años» como lo denominaron. Para conmemorarlo colocaron dos mojones de piedra a manera de «huancas» en señal imborrable de este histórico reencuentro. Luego tuvieron lugar los discursos y cuando le tocó el turno al líder de los visitantes escuchamos la versión de cuando la nación cañar se enteró de la captura del inca Atahuallpa por parte de las huestes capitaneadas por Pizarro, inmediatamente se enviaron con destino a Cajamarca cien mil guerreros cañaris con la finalidad de liberar al Inca de prisión. Lamentablemente, en el camino se enteraron que lo habían asesinado y entonces entre los expedicionarios cundió el desaliento y la desazón, ya no llegaron a Cajamarca y casi todos emprendieron el camino de regreso. Pero hubo algunos hermanos que no regresaron por varios motivos y se quedaron a vivir en tierras pobres, solos y abandonados, resistiendo a los invasores. Luego de 500 años venían de Cañar para reencontrarse con sus hermanos de sangre.

3 Con la finalidad de facilitar el traslado de una persona desde el lugar o hasta el lugar de destino se acostumbra designar a un lugareño de confianza, apropiado para estos menesteres y que tenga el tiempo para hacerlo. A esta persona se le denomina «propio» y prácticamente su misión es asegurar el traslado de esa o esas personas en las mejores condiciones, lo que incluye también la preocupación por la acémilas, la orientación por el camino 
Regresando al conversatorio diremos que fue una oportunidad para que los cañaris presentaran los problemas de sus pueblos, formularan pedidos y obtuvieran compromisos de las autoridades para solucionar los problemas planteados4. Lo que llamó la atención es que don Víctor Huamán Reyes no participó en el evento, permaneció mayormente en su propia casa. Se le veía atareado, atendiendo y conversando con gente. Su casa se llenó de huéspedes, de personas que comían de su generosa cocina o de conocidos suyos que llegaban para saludarlo.

Si bien el evento oficial se realizó de manera exitosa y se celebraron compromisos de realizar obras importantes en el ámbito del distrito, que tardarían años en cumplirse parcialmente, nos llamó la atención la ausencia del cacique en el programa del evento, hecho que se puede interpretar como su distanciamiento político de la comitiva visitante, relacionarlo con el hecho de que no era autoridad oficial o se puede interpretar también como una forma de discriminación de las autoridades locales que no eran naturales de Cañaris. Luego me pareció escuchar que para presentar los problemas se necesitaban personas mejor relacionadas con ese mundo oficial como era el caso de los profesores, del alcalde y del jefe del sector educación, todos ellos foráneos.

Ya en este tiempo tuvimos la impresión que don Víctor Huamán Reyes contemplaba el ascenso de un nuevo tipo de liderazgo representado por jóvenes más instruidos que con el tiempo se desempeñarían como autoridades municipales y educativas. Justamente un corto tiempo después de la visita de las autoridades departamentales, uno de esos jóvenes líderes se convertiría en el nuevo alcalde distrital, gracias a la promoción realizada por las autoridades visitantes. Don Víctor se mantendría en oposición a estos nuevos liderazgos, a pesar de la participación de sus familiares directos en cargos de autoridades y dirigentes comunales.

\section{DON VÍCTOR HUAMÁN REYES iENTRE DOS MUNDOS?}

Existen varias referencias sobre el doble rol que desempeñaron los caciques en tiempos coloniales, un rol funcional al sistema de explotación y dominación colonial y otro representando a la población originaria. Resistencia y colaboración son dos términos utilizados para calificar este doble rol. Sin embargo en tiempos republicanos es posible que un líder étnico se haya visto en el dilema de jugar similares roles: uno de colaboración con la sociedad nacional y otro de resistencia. En el primer caso desempeñando funciones dentro del aparato estatal a niveles locales y en el segundo asumiendo cargos no oficiales, más propios de la sociedad originaria.

La vida de don Víctor Huamán Reyes es un ejemplo de este doble nivel de actuación de algunos líderes indígenas de Cañaris y espacios similares. Es posible que este doble rol reforzara su liderazgo local, pero tenemos la impresión que su prestigio se basaba en otras bases y no se extinguía cuando terminaba su cargo oficial. Uno de los temas que no podemos ignorar es que hay referencias de un trato autoritario y de imposiciones a las

y las necesidades de información de la persona que va o viene del lugar. He visto que esta labor se le encarga a personas jóvenes o más bien humildes a las que se les reconoce esa labor con un pago o la liberación de algunas obligaciones comunales.

4 Se publicó un informe resumen del evento bajo el título de Parlashanshkita Cañaripe (Alva \& Roque, 1986) en la que se puede apreciar un largo listado de pedidos de casi todos los caseríos del distrito y los compromisos asumidos por sus autoridades. Destacan los memoriales de pedidos respaldados por huellas digitales como testimonio de carácter de iletrados de la mayoría de los pobladores. En este informe no aparece ni siquiera mencionado el cacique de Cañaris. Hecho que revela su carácter de autoridad no oficial. 
personas, que igualmente sería «el otro lado» de la función del cacique. Pero esta conducta puede ser explicada si nos colocamos en un contexto social, como el de Cañaris, en que el Estado no puede jugar su papel coercitivo (policía, multas, sanciones) y éste tiene que ser asumido por quien representa la autoridad. En este sentido se comenta, por ejemplo, que sin la exigencia y presión de los mayores y en especial de don Víctor Huamán no se hubiera construido el nuevo templo de Cañaris. Sobre el particular existen referencias a castigos o multas que se imponían a los comuneros que se negaban a participar en las faenas comunales, hacían mal el trabajo o simplemente se «portaban mal».

Nos parece pertinente presentar la ficha personal de don Víctor Huamán Reyes y la relación de cargos más importantes desempeñados a lo largo de su vida. A través de esta información se podrá notar esta existencia «entre dos mundos» de ciertos líderes andinos.

\section{1. Ficha personal del cacique de Cañaris}

Nombres: Víctor Huamán Reyes

Lugar de nacimiento: sector Atunpampa (Cañaris)

Lugar de residencia: sector Atunpampa (Cañaris)

Padre: Teodoro Huamán Rodríguez (fue autoridad comunal)

Madre: Agapita Reyes Tantarico

Abuelo materno: José Manuel Blanco Reyes Tantarico (líder comunal y hombre «de plata»)

Abuelos paternos: Bruno Huamán y Viviana Rodríguez (natural de Incahuasi)

Hermano: Vicente Huamán Reyes (murió apuñalado cuando era joven)

Esposa: María Estebana Huamán, natural de Mitobamba (Cañaris)

Idiomas: quechua como idioma materno y castellano como segunda lengua

Estudios: primaria incompleta en escuela de Colasay (abandono por muerte de su padre, cuando don Víctor tenía 22 años aprox.)

Edad actual: 89 años. Nació el 6 de marzo de 1918.

Ocupación habitual: agricultor y pequeño ganadero

Propiedades: casa en Atunpampa, casa en Cañaris. Chacras: Succha (Atunpampa, 3 ha; Lique, 15 ha; Montaña de Tute, 100 ha; Atunyacu de Tute, 4 ha). Todo está dividido en herencia para sus familiares

Los cargos oficiales:

- Secretario de Juez (i1945?)

- Juez de Paz Accesitario (1949)

- Juez de Paz de primera nominación (1952, 1961, 1970, 1971)

- Teniente gobernador. Varios años

- Alcalde distrital de Cañaris (encargado1969)

Los cargos no oficiales:

- Gestor del reconocimiento de la Comunidad Indígena de Cañaris (1951)

- Personero Legal de la Comunidad Indígena de Cañaris (por 9 años)

- Mayordomo de la Festividad San Juan Bautista 
- Promotor en la construcción del templo de Cañaris

- Promotor en la construcción del local policial

- Líder de la parte baja de la Comunidad en las faenas de limpieza de caminos

- Presidente de los Danzantes de Cañaris

\section{EL DEPOSITARIO DE LA MEMORIA. EL RITUAL DE LOS TÍTULOS}

Resulta por demás paradójico que el propio Estado que había cancelado la existencia jurídica de las comunidades indígenas durante más de un siglo, exigiera en el expediente de solicitud de reconocimiento oficial de la comunidad la presentación de los títulos de propiedad como una de las tres condiciones. Lo cierto es que las comunidades en todo el país recurrieron entonces a buscar los documentos coloniales guardados durante tantos años por sus dirigentes y/o a tramitar copias de esos documentos ante las oficinas públicas que habían heredado los archivos de la administración colonial.

Lo cierto que en las conversaciones con don Víctor Huamán Reyes, sostenidas en febrero de 1987 y octubre de 1993, aparece información de que su abuelo materno, José Manuel Blanco Reyes, fue el «guardador» de esos documentos que, al parecer, fueron traídos de un archivo notarial de Piura por una comisión integrada por tres personas que hicieron el largo viaje hasta Piura y para lo cual prepararon «dos pares de buenos llanques» (ojotas). Entre los comisionados figuraban el abuelo materno de don Víctor y Cornelio Huamán. Es posible que otros legajos de esos títulos coloniales tuvieran otro origen ya que existen títulos de las partes altas (Congona) y bajas (Illambe).

Don Víctor recuerda que cuando «era chico», los mayores — anualmente- soleaban esos títulos de la comunidad sobre mantas nuevas y gente mayor venían al lugar elegido con aguardiente de caña y las mujeres (viudas y mayores) preparaban todo tipo de comida. Eso se hacía en el sector llamado Quinua y antes lo hacían en el sector Sábila, ambos sectores limítrofes eran amenazados por los hacendados vecinos. Don Víctor recuerda que una de las casas en que se «secaban» los títulos pertenecía a Fernando Mendoza y a quien los hacendados perseguían para quitarle los títulos. Al fallecer Manuel Blanco Reyes, los títulos son recogidos por Isabel (sic) Reyes Tantarico que vivía en Quinua, hijo de Manuel Blanco Reyes Tantarico y tío de don Víctor Huamán. Isabel guardó esos títulos en su casa, pero ciertas veces como «cuando vino la montonera» los escondía «en la peña Kerguer del Cerro Lique» ubicada en las cercanías. Al fallecer Isabel, fue su mujer, Josefa Huamán Pariacurí, la encargada de revelar el sitio en que se guardaban los documentos y fue ella la que condujo a tres personas confiables (Nicolás de la Cruz, Ciriaco de la Cruz y Víctor Huamán Reyes) al lugar exacto donde estaban escondidos los documentos: «los hallamos en una caja de madera, muy malograda y se habían manchado algunos papeles», recuerda don Víctor Huamán5.

5 Esta versión del cacique fue respaldada por otro descendiente de antiguos dirigentes comunales que da detalles adicionales: «Eusebio Reyes Isidro fue también un guardador de los títulos de la comunidad. Las mujeres viudas y solteras de más de veinte años le llevaban leña a su casa y los comuneros le techaban su casa. En aquel tiempo los letrados se reunían con mucho respeto para leer los títulos. Las mujeres se arrodillaban, rezaban el bendito y saludaban una por una a todos los hombres letrados. Ellas traían mantas, las mejores, para solear los documentos» (entrevista a Pedro Bernilla, junio de 1987).

En este caso podría tratarse de otro grupo de títulos comunales porque el cacique admite que hay por lo menos dos expedientes de títulos comunales: él poseía uno de ellos, y el otro lo tenía Pablo Huamán que fue «otro cacique» ya muerto que conservaba los títulos del río para allá, es decir de la parte alta. 
Mediante este mecanismo de tradición familiar6, el joven Víctor Huamán Reyes se convirtió en el guardián de dichos documentos que en cierta forma conservan la memoria colectiva de la lucha de los cañaris por su territorio, ambicionado por los hacendados de Jaén. Fue justamente la noche que me alojé en su casa que el cacique me mostró los títulos comunales, que constaban de varios folios, escritos en texto y papel antiguo rápidamente identificable y fechado en la primera mitad del siglo XVIII y entonces lo narrado por él adquirió de pronto visos de veracidad. Esos añejos documentos, si bien pudieron ser celosamente guardados, difícilmente pueden ser leídos por dirigentes quechuahablantes casi iletrados y de allí la versión de que «estaban escritos en latín». Incluso la parte que relata que los títulos fueron escondidos en un cerro se volvían creíbles a juzgar por las evidentes manchas que lucían algunos folios y que podrían haber sido causadas por las filtraciones de agua.

Se trataba de documentos originales con los sellos propios de los primeros años del siglo XVIII, tanto el tipo de papel, la tinta y el tipo de letra eran inconfundiblemente originales. Una breve mirada a dichos documentos hizo emerger de sus páginas la figura de doña Juana María Callaypoma como cacica de Cañaris e hija de don Sebastián Callaypoma, cacique de Penachí. Penachí era otro pueblo quechua hablante cercano a los cañaris y más pegado a la costa de Lambayeque y probable cabeza de un curacazgo tardío que abarcaba los pueblos o común de indígenas de Salas, Penachí, Cañaris e Incahuasi.

El papel de don Víctor Huamán Reyes como guardián de los títulos comunales se revela a toda la población cuando se constituyen en los documentos más importantes para la obtención del reconocimiento oficial de la Comunidad Indígena San Juan Bautista de Cañaris, reconocimiento obtenido el 10 de octubre de 1958.

\section{LA IMPORTANCIA DE SER FUNDADOR}

Tuve la oportunidad de conocer otro aspecto de la vida de don Víctor Huamán Reyes con ocasión de una reunión de trabajo con la joven directiva de la Comunidad Campesina San Juan de Cañaris, interesada en aprovechar todo este interés despertado por el emergente gobierno del APRA en relación a la titulación del territorio de comunidades campesinas y del reconocimiento oficial de nuevas comunidades. Gracias a esa conversación y a la revisión de documentos de la Comunidad me pude dar cuenta que dicha comunidad contaba con reconocimiento oficial y había realizado gestiones parcialmente exitosas para su titulación territorial. Me llamó la atención la aparición de transcripciones de documentos coloniales realizados por técnicos del Ministerio de Trabajo y Asuntos Indígenas durante la parte final de la década de 1960. En uno de los documentos del expediente administrativo se mencionaba a don Víctor Huamán Reyes como «gestor» del reconocimiento de la Comunidad Campesina San Juan de Cañaris. Era evidente que, treinta años atrás, el cacique de Cañaris había jugado un rol importante en este proceso de refundación de la comunidad campesina.

Al regreso de la celebración del aniversario de la Comunidad San Juan de Cañaris (octubre de 1993) fui invitado por don Víctor Huamán Reyes a descansar en su residencia. Luego de los saludos protocolares y del respectivo trago ceremonial con aguardiente de caña reiniciamos la conversación sostenida el año 1987. Aprovechamos entonces para recorrer la huerta en que se cultivaban diversos frutales destacando naranjos, limas, granadilla y

6 Chantal Caillavet (1985) en un breve trabajo sobre los saraguro de Ecuador nos llama la atención sobre la importancia para la historiografía que tienen los archivos familiares que, por algún interés específico, son conservados a través de generaciones. Las referencias encontradas por nosotros refuerzan la importancia de desarrollar esta línea de investigación. 
huabos. En otra parte tenía maizales y yucas. En la conversación nos contaba que tenía otras chacras en otros lugares de mayor altura en donde cultivaba maíz, ollucos, ocas y criaba ganado mayor. Este relato nos hizo recordar a John Murra y su teoría de control de pisos ecológicos como una estrategia de sobrevivencia andina. De hecho era una persona acomodada aunque sus signos exteriores de riqueza se limitaran a tener la mejor acémila del distrito y tenerla bien enjaezada, lucir una casa rústica pero amplia con todas las comodidades y la siempre alabada generosidad con sus visitantes.

Gran parte de la noche, alumbrados con una lámpara a kerosene —como en todo el distrito- y con el ocasional resplandor del fogón de la cocina, iniciamos una larga conversación en la que me dio la impresión que don Víctor Huamán estuvo más interesado en hacerme hablar, en interrogarme sobre variados asuntos del mundo urbano que le interesaban. Al momento que le formulaba preguntas sentía que me respondía con ciertas ambigüedades, con respuestas un poco fuera de lugar o simplemente con recuerdos de mucho tiempo atrás. Pero a medida que avanzaba la noche la confianza se acrecentaba y poco a poco los asuntos de los cañaris fueron apareciendo.

El tema del reconocimiento oficial de la Comunidad Campesina San Juan de Cañaris se revelaba como el más importante no solo para insertarse en el mundo oficial y evitar todas las secuelas de la discriminación, sino que se vio como más urgente cuando el territorio comunal fue seriamente amenazado por una invasión producida en el sector Huacapampa y protagonizada por gente proveniente de la serranía de Cajamarca alentada por la propaganda oficial de la colonización de la selva. A estos invasores los cañaris les denominarían despectivamente como «provincianos» que es el equivalente a foráneos y que posiblemente hacía referencia a que la mayoría de ellos provenían de las provincias de Chota y Cutervo pertenecientes al departamento de Cajamarca. Huacapampa era un lugar muy productivo con grandes extensiones de bosques ya que se define como ceja de selva y que resulta ideal para el tipo de colonización promovida desde el Estado.

La comunidad movilizó sus energías para avanzar en el reconocimiento oficial porque sin ese requisito no podía litigar en los tribunales ni siquiera en las reparticiones públicas. Es en este momento en que el papel de don Víctor Huamán Reyes, como «guardador» de los títulos coloniales fue crucial porque tenía acceso a parte importante de los documentos históricos que respaldaban la propiedad comunal —indispensables para anexarlos en el expediente de reconocimiento-.

El otro documento que exigían los funcionarios era un croquis o plano general del territorio comunal y es allí donde los cañaris se encontraron con dificultades porque no reconocían linderos tan precisos, tan solo de lugares limítrofes como: el río Huancabamba (río Grande de Pucará), la laguna Tembladera, la laguna Shin Shin, el sector Huacapampa, Congona, Quinua, Sábila, Quebrada Tocras. Esta dificultad de reconocer exactamente los linderos comunales no es solo de los cañaris, lo hemos comprobado en otras comunidades?.

Otro de los requisitos para el reconocimiento fue el censo de la comunidad realizado por los dirigentes, que los lleva a entrevistar casa por casa, caminando días y noches para contar a todos los pobladores y a sus respectivos ganados. El resultado arroja 1817 habitantes, de los cuales 399 eran hombres adultos y 415 mujeres adultas, se contaron también 523 hombres menores y 480 mujeres menores. El censo de ganado arrojaba: 1765 vacuno,

7 Susan Ramírez en su trabajo el Mundo al Revés (1996) argumenta que en el mundo andino no existió el concepto de propiedad privada de la tierra y explica las dificultades de las comunidades para sustentar, con planos, linderos y medidas exactas, sus derechos territoriales frente a los españoles. Esta tesis nos estaría explicando las dificultades que han tenido muchas comunidades campesinas, a las cuales hemos acompañado, para sustentar debidamente sus derechos territoriales actuales a pesar que la mayoría de ellas cuentan con documentos coloniales, aunque no perfectamente delimitados, salvo en zonas de litigio. 
1701 ovejuno, 85 caballar, 128 asnal, 186 mular y 847 porcinos. Así consta en un documento elevado al Director General de Asuntos Indígenas del Ministerio de Trabajo y Asuntos Indígenas con fecha 26 de marzo de 1956.

La participación de don Víctor Huamán Reyes se hace también necesaria porque probablemente era uno de los hombres «más letrados» de Cañaris y hablaba muy bien el castellano ya que la mayoría de líderes eran monolingües o no dominaban el castellano. Obviamente para hacer los trámites se necesitaba una persona de las características del cacique. Se sabe que viajó repetidas veces al pueblo de Salas (por un tiempo Cañaris perteneció al distrito de Salas) en busca de asesoramiento, viajó también a la ciudad de Chiclayo y hasta en dos oportunidades viajó a Lima con la finalidad de avanzar el reconocimiento de la Comunidad8. Luego haría otros viajes para la titulación del territorio comunal y en esta oportunidad acompañando a Romualdo Bernilla Reyes, presidente de la Comunidad en aquel tiempo.

Gracias a este expediente los comuneros logran obtener su reconocimiento oficial el 10 de octubre de 1958 mediante una Resolución Suprema firmada por el Ministro de Trabajo y Asuntos Indígenas. Este documento es clave para que los comuneros realizaran una exitosa defensa de su territorio comunal amenazado por los provincianos en el sector Huacapampa, y en una jornada memorable para ellos logran que el cabecilla de la invasión, un técnico dental Ilamado Flores Guivar, sea cercado por los cañaris y salva su vida escapándose disfrazado de mujer como lo cuentan festivamente los comuneros. Los cañaris no solo logran defender su territorio sino que logran que los invasores reconozcan la propiedad comunal, se incorporen a la Comunidad Campesina y se desenvuelvan como uno de los más importantes y progresistas sectores.

La información disponible nos habla que don Víctor Huamán si bien no encabezó estos niveles de enfrentamiento, él mismo nos dirá que no apareció porque «su asesor legal se lo recomendó ante el peligro de muerte», pero su actuación fue decisiva en el reconocimiento oficial y gracias a ese reconocimiento se logra una defensa exitosa del territorio comunal. El reconocimiento oficial de la comunidad implica hasta cierto punto una especie de refundación de la comunidad porque hasta entonces estaba «oficialmente muerta», sin posibilidades de litigar en los tribunales y en riesgo de desaparecer dada la expansión constante de las haciendas vecinas y de los colonos.

Luego del proceso de reconocimiento los comuneros se lanzaron al proceso de titulación oficial del territorio comunal, proceso que se dilató por mucho tiempo debido a la inexistencia de una ley especial para ello. Este proceso iniciado por don Víctor Huamán Reyes es continuado por otros dirigentes como Romualdo Bernilla del sector Illambe. Estos trámites dan como resultado que una comisión oficial, nombrada por Resolución Ministerial del entonces Ministerio de Trabajo y Asuntos Indígenas levantara un plano de la

8 La construcción del nuevo templo de San Juan Bautista y la obtención del reconocimiento de la comunidad, a las cuales estuvo muy vinculado don Víctor Huamán Reyes, están emparentados con relatos míticos. Existe la versión de que las campanas del templo fueron sacadas del cerro mágico de Angash en un acto de valentía de «los mayores» que lograron burlar al dragón que resguardaba esas dos campanas de oro y plata y que por ello tenían un sonido muy especial. Esas campanas desaparecieron del local del puesto policial de Cañaris en donde fueron temporalmente colocadas mientras se construía el nuevo templo. Por su parte, don Víctor Huamán Reyes cuenta a su familia (versión de su hijo Julio) que para el reconocimiento de la comunidad tuvieron que entrar a una cueva del cerro El Alumbral, ubicado cerca de la casa del cacique y allí encontraron como una mesa de material especial, «posiblemente oro» a la cual le arrancaron con gran dificultad trocitos que colocaron en una bolsita de tela y «con parte de eso viajaron a Lima para el reconocimiento». Esa cueva se ha tapado ya. Lo cierto es que el «frontis» del templo de Cañaris era el lugar en donde se reunían los mayores para tomar las grandes decisiones, como la limpia de caminos, las gestiones ante las autoridades departamentales. Don Víctor recuerda con mucha nostalgia que cuando «era chico, mi papá me llevaba a esas reuniones y escuchaba hablar a los mayores hasta dormirme». 
Comunidad con su respectiva memoria descriptiva pero que no fueron aprobados porque el golpe militar del año 1968 cortaría este proceso.

En el año 1992 y otra vez gracias a estos títulos coloniales, transcritos al español moderno, y a los avances logrados durante la década de los sesenta, la comunidad de Cañaris logra titular oficialmente su territorio comunal y reivindicar territorios perdidos en los largos años de sordera oficial. El papel desempeñado en todo este proceso por don Víctor Huamán es reconocido por la nueva dirigencia comunal que lo invita para la ceremonia oficial de entrega de títulos comunales expedidos por una dependencia del Ministerio de Agricultura. Habían pasado 171 años de la independencia de España para que el Perú oficial reconociera la propiedad comunal de los cañaris de Lambayeque. Don Víctor Huamán Reyes estaba asociado a esta reivindicación histórica.

\section{TAMBIÉN DIRECTOR DE LOS DANZANTES DE CASCABEL}

En una de las festividades de San Juan a fines del año 1987, fui gratamente sorprendido por la súbita presentación de los danzantes de Cañaris que, habiendo practicado durante horas en una de las casas de los danzantes y de haber libado algunas copas de licor, hacían su aparición comandados por don Víctor Huamán Reyes que no solo los había convocado, sino también los había agasajado, ayudado a reencontrar sus ritmos y luego persuadido para que hicieran su aparición pública. Eran apenas ocho los danzantes que seguían el ritmo de un «mamita» o músico que hacía brotar de una rústica trompeta (dulzaina) de madera una música muy especial, acompañado de un tambor hecho con cuero. La vestimenta de los danzantes era del diario, salvo el detalle de sus ponchos cruzados en el tórax, un atuendo de carrizos en la cabeza y blandían unas espadas de madera llamadas palios. Solo dos danzantes tenían atados a una de sus piernas unos «cascabeles», a manera de sonajeros. Era evidente que a los danzantes les faltaba entrenamiento y se habían pasado de licor, pero igual congregaron a la gente y constituyó todo un espectáculo.

Lo llamativo fue la presencia de don Víctor Huamán en todo este proceso y más notable todavía porque hacía las veces de «autor» o director de la danza, es decir el que marcaba los pasos, el que ordenaba los cambios y el que tomaba decisiones con una concentración de experto. Todo parece indicar que el cacique no tuvo interés en que la presentación de los danzantes apareciera en el programa oficial del evento, simplemente decidió presentarlo en el momento y condiciones que a él o al grupo le pareció adecuado. Yo sentía que en el medio de este asunto estaba la evidente rivalidad entre el cacique y las nuevas autoridades comunales y municipales que respondían a una determinada política que parece no era compartida por el cacique y su gente.

En una de las escuetas conversaciones con uno de sus hijos pude comprobar que una de las funciones — de tiempo atrás — del cacique era la de ser «director» de los danzantes de Cañaris y que en cierta ocasión la danza se había presentado en Chiclayo y en la provincia cajamarquina de Santa Cruz. Con el tiempo y siempre en la residencia del cacique esa afirmación era respaldada con un diploma de agradecimiento expedido por una entidad gubernamental el año 1973 y luego una constancia de haber participado, el año 1974, en el Encuentro Inkarrí.

El hecho de haber presentado a los danzantes, en esas ocasiones, fue muy importante porque despertó el interés por rescatar esta danza del práctico olvido y ostracismo a la que estaba condenada y fueron justamente dos profesores quechua hablantes (Quispe y Chucas) los encargados de presentarlos nuevamente en Chiclayo y este último de recopilar algunos de los momentos o pasos de la danza y formar un equipo de jóvenes que le han 
dado continuidad hasta el presente. Uno de esos niños, José Gaspar Huamán, convertido en profesor bilingüe, es uno de los animadores de la danza de Cañaris y hace poco la pudo lucir en Chiclayo exhibiendo más pasos o momentos de la danza: el golpe, el palio, el gavilán, el cascabeleo, el sombrero, la casaca y la borrachera (o «despedimento»). Lamentablemente no han sido los hijos del cacique los continuadores de la danza y en parte porque el propio cacique no fue un buen danzante, pero sí era un buen director y como reconocen los nuevos danzantes «la danza era el encanto del cacique». Felizmente parece que los nietos del cacique darán continuidad a la tradición: uno de ellos tiene habilidades para la danza, y don Víctor le ha obsequiado uno de sus juegos de cascabeles para su primera presentación en la feria patronal de Atunpampa.

Don Víctor Huamán Reyes era un hombre que «estaba» en todas las cosas importantes de su pueblo y en ellas jugaba un papel central. En este caso aparecía motivando y promoviendo las danzas rituales y al hacerla aparecer en momentos importantes se convierte en refundador de un proceso que revitaliza una danza en proceso de extinción.

\section{LA IMPORTANCIA DE LA GENTE}

La segunda mitad de la década de los ochenta es un periodo de gran dinamismo para las comunidades campesinas gracias a los espectaculares Rimanacuy organizados por el gobierno, a la donación de dinero, maquinaria agrícola y la expedición de dos normas que facilitaron el reconocimiento y la titulación de territorio de las comunidades.

Es en este contexto de dinamismo de las comunidades que la dirigencia comunal realiza un evento de capacitación (a mediados de 1987) para tratar el tema de los estatutos de la comunidad, y para esa ocasión asiste un alto funcionario del Ministerio de Agricultura. Luego de las palabras del Presidente de la Comunidad, inicia su exposición el mencionado funcionario en su clásico estilo de autoridad citadina y es en esas circunstancias que hace su aparición en el recinto don Víctor Huamán Reyes, asoma la cabeza, da una mirada a la mesa, avanza unos pasos, la gente como que lo saluda y sin más miramientos ingresa al recinto e inicia un largo ritual de saludos a los más de 35 asistentes. Mientras tanto el funcionario suspendió su alocución haciendo evidente su molestia por la irrupción. Sin embargo nadie reclamaba y todos parecían sentirse a gusto con la presencia del cacique. Luego de terminado su largo saludo el cacique se acercó muy amablemente a la mesa y sacando una botella de aguardiente, sirvió una copita y me la ofreció agradeciendo mi presencia y deseándome buena estadía. Acepté el trago, lo tomé y le devolví la copa con el ruego de que no prosiguiera con su brindis porque el funcionario estaba en uso de la palabra. El cacique, con un movimiento de cabeza, como indicando cierta incomodidad, se alejó para sentarse a participar en la reunión, como si nada extraño hubiera ocurrido. Según las normas del protocolo de los cañaris9 la copa con aguardiente que me brindaba con tanta amabilidad el cacique se la debí pasar al funcionario porque yo era el que lo conocía y sabía de su jerarquía; pero no lo hice ante el temor de un desplante a la cortesía de don Víctor Huamán Reyes. Por supuesto que el funcionario aprovechó parte de su

9 Se trata de una ceremonia de respeto y de diferenciación de rangos al interior de un grupo. Para agasajar a una persona, pedirle un favor o simplemente darle la bienvenida se hace todo un rito que consiste en que la persona que ofrece el licor — generalmente aguardiente de caña producido en alambiques de los poblados vecinos- sirve una copa y se lo ofrece con respeto o cariño a la persona a la cual él considera motivo de su ofrecimiento. Esta persona puede tomar la copa, pero si entre el grupo hay una persona que para él le merece respeto (digamos de mayor jerarquía) le cede la copa a esta persona y puede que ésta le pase la copa a otro de mayor nivel. Una vez que llega a la cúspide la copa va siendo tomada en escalones descendentes hasta llegar a la persona que ha ofrecido la «media» (en alusión a la media botella con que generalmente se compra el aguardiente). 
discurso para hablar de lo dañino que resulta el licor en las comunidades, pero no se atrevió a más y casi como una ironía, esa fue su última actividad como tal porque al regresar a la capital departamental se enteró que había sido cesado en el cargo.

Aprovechando el almuerzo e intrigado por el incidente protagonizado por don Víctor Huamán aproveché para hablar sobre el tema con el mismo protagonista, obteniendo como respuesta «cómo no voy a saludar a mi gente» y luego describía los lazos de sangre, amistad, de parentesco y económicos que lo unían con muchos de los asistentes y que era impensable que entrara al recinto y no los saludara. Me alejé pensando que el cacique tenía otra comprensión de respeto y buenas maneras, pero que había que considerarse realmente una autoridad para hacer lo que hizo.

\section{CONCLUSIÓN}

Queda demostrado cómo algunos aspectos de la vida de un hombre nos sirven para iluminar hechos sociales, procesos de una comunidad y la lucha esforzada de una persona por aparecer en los grandes asuntos de su pueblo, brillar y quedar en la memoria de su gente, siguiendo así la tradición andina de los ancestros (Ramírez, 2002). La defensa del territorio comunal, conservar la herencia de los ancestros, el guardar la memoria del pueblo, el preservar las danzas rituales, el manejarse entre dos mundos para «servir a la comunidad», el ritual de los documentos, la práctica de la reciprocidad, la hospitalidad, y el hecho de ser fundador de la comunidad han convertido a don Víctor Huamán en un «cacique moral» de los cañaris.

Contrariamente a lo que puede pensarse, el liderazgo de don Víctor se reforzó también con sus relaciones con el mundo oficial y el manejo de esas relaciones en provecho de su comunidad. Solo así puede entenderse su tardía matrícula en una escuelita pública a la edad de 20 años, su larga amistad con asesores de Salas y Chiclayo, y las atenciones a las autoridades que visitaban a su pueblo. En Colasay se despertó su interés por la defensa de la comunidad, en Salas y Chiclayo obtuvo el acompañamiento de personas influyentes en trámites ante las autoridades oficiales. Esta vinculación con el mundo oficial, no parece haberlo debilitado, sino todo lo contrario.

A la luz de estos resplandores en la vida de don Víctor Huamán Reyes se tiene la impresión que muchos aspectos importantes del mundo originario se nos están escapando literalmente de las manos. Se tiene la impresión de que «lo andino» simplemente ya fue, es decir es pasado, nunca presente; este trabajo nos llama la atención sobre las «sobrevivencias andinas» a las cuales debemos estar atentos.

Reconforta saber que seguramente en otros espacios hay personas que como don Víctor Huamán Reyes representan lo que podríamos decir un «cacique moral», tal vez no existan ya muchos o tal vez falten personas que escribieran sus historias porque en este mundo, no en todos, solo la escritura perenniza a las personas y sus obras. Y la vida de este personaje nos recuerda que no se trata del brillo griego de los grandes discursos o del brillo romano ganado en victoriosas batallas (Arendt, 2003), se trata más bien del brillo que da el servir a la gente, servir a la «comunidad». 


\section{Referencias citadas}

ALVA MARIÑAS, P., 1989 - El sitio Arqueológico de Chiñama. Revista Alternativa, 10: 111-126; Chiclayo: Centro de Estudios Sociales Solidaridad.

ALVA MARIÑAS, P., 1995a - Congona: un sitio formativo en la serranía de Lambayeque. Revista Avances. Apuntes para la investigación regional, I: 9-24; Chiclayo: Instituto de Desarrollo Regional.

ALVA MARIÑAS, P., 1995b - Pachacamác en la serranía de Lambayeque. Revista Utopía Norteña, 2: 231-235; Lambayeque: Facultad de Ciencias Histórico Sociales y Educación de la Universidad Nacional Pedro Ruiz Gallo.

ALVA MARIÑAS, P., 1999 - El curacazgo andino de Lambayeque. Ponencia presentada en el Seminario Internacional «Lambayeque y el Perú, dos milenios de historia»; Chiclayo: Instituto de Desarrollo Regional.

ALVA, P. \& ROQUE, P., 1986 - Parlashashkita Cañaripe. Informe del I Panel Fórum de Cañaris; Chiclayo: CICAP.

ARENDT, H., 2003 - ¿Qué es la autoridad? Entre el pasado y el futuro. Ocho ejercicios sobre reflexión política, 430 p.; Barcelona: Ediciones Península.

CAILLAVET, C., 1985 - Fuentes para la historia andina: los archivos privados indígenas de la zona de Saraguro. Boletín de los Museos del Banco Central del Ecuador, 5: 86-90; Quito. Miscelánea Antropológica Ecuatoriana.

COCK, G., 1984 - Poder y riqueza de un Hatún Curaca del Valle del Jequetepeque en el siglo XVI. Historia y Cultura, 17: 133-155; Lima.

DIEZ HURTADO, A., 1988 - Pueblos y caciques de Piura, siglos XVI y XVII, 64 p.; Piura: Centro de Investigación y Promoción del Campesino.

ESPINOZA SORIANO, W., 1980 - El curaca de los Cayambes y su sometimiento al imperio español, siglos XV y XVI. Bulletin de I'Institut Français d'Études Andines, 9 (1-2): 89119; Lima.

FERNÁNDEZ VILLEGAS, O., 1991 - Un curaca de la sierra central del Perú (siglo XVII). Boletín de Lima, 13 (78): 49-55; Lima.

GLAVE, L. M., 1989 - Un curacazgo Andino y la sociedad campesina del siglo XVII. Allpanchis, 21 (33): 11-39; Sicuani.

PEASE, F., 1988 - Curacas coloniales: Riqueza y actitudes. Revista de Indias, 48 (182-183): 87-107; Madrid.

RAMÍREZ, S. E., 2002 - El mundo al revés: contactos y conflictos transculturales en el Perú del siglo XVI, 349 p.; Lima: Fondo Editorial de la Pontificia Universidad Católica del Perú.

RAVINES, R., 1972 - Los caciques de Paucamarca. Algo más sobre las etnias de Chachapoyas. Historia y cultura, 6: 217-48; Lima: Museo nacional de arqueología, antropología e historia del Perú.

ROSTWOROWSKI, M., 1961 - Curacas y sucesiones. Costa Norte, 136 p.; Lima: Librería Imprenta Minerva Miraflores.

ROSTWOROWSKI, M., 1982 - Testamento de Don Luis de Colan: Curaca en 1622. Revista del Museo Nacional, 46: 507-43; Lima. 